\title{
Clinical Predictors of Cetuximab for First-Line Therapy of Metastatic Colorectal Cancer: A Single Institutional Retrospective Study
}

\author{
Yuki Morishita1*, Hiroaki Tanioka², Motoi Asano², Kotomi Tokuyama1, Hiroko Okamoto1, \\ Tomohisa Okamoto', Takako Oda' ${ }^{1}$, Masatoshi Ohta1, Masayuki Fukuzawa1 \\ ${ }^{1}$ Department of Pharmacy, Okayama Rosai Hospital, Okayama, Japan \\ ${ }^{2}$ Department of Medical Oncology, Okayama Rosai Hospital, Okayama, Japan \\ Email: ^mrshtyk@gmail.com
}

How to cite this paper: Morishita, Y., Tanioka, H., Asano, M., Tokuyama, K., Okamoto, H., Okamoto, T., Oda, T., Ohta, M. and Fukuzawa, M. (2017) Clinical Predictors of Cetuximab for First-Line Therapy of Metastatic Colorectal Cancer: A Single Institutional Retrospective Study. Journal of Cancer Therapy, 8, 827-837. https://doi.org/10.4236/jct.2017.89072

Received: August 19, 2017

Accepted: September 9, 2017

Published: September 12, 2017

Copyright $\odot 2017$ by authors and Scientific Research Publishing Inc. This work is licensed under the Creative Commons Attribution International License (CC BY 4.0).

http://creativecommons.org/licenses/by/4.0/

\begin{abstract}
Predictive factors of cetuximab efficacy for metastatic colorectal cancer (mCRC) have not been sufficiently revealed. The present study aimed to explore new predictors. A total of 30 patients with KRAS exon 2 wild-type unresectable $\mathrm{mCRC}$, who had been treated with cetuximab-based regimen as first-line therapy, were retrospectively analyzed. We assessed whether gender, age, primary tumor site, RAS genotype, the Eastern Cooperative Oncology Group Performance Status (ECOG PS), metastatic status, histological grade, carcinoembryonic antigen (CEA), treatment regimen, and oxaliplatin-based adjuvant chemotherapy at baseline were associated with cetuximab efficacy. Progression-free survival (PFS) and objective response rate (ORR) were evaluated and statistically analyzed. Analysis of PFS revealed that left-sided tumor and good PS had relevance to good results. PFS among patients with left-sided CRC was longer than that among those with right-sided CRC (median, 10.6 and 3.5 months, respectively). Patients with a PS of $0-1$ experienced significantly longer PFS than those with a PS of $2-3$ (median, 8.6 versus 1.3 months, respectively). In analysis of ORR, high histological grade and serum CEA level showed interaction with good effect. Patients with histological grade I/II cancer experienced better ORR than those with histological grade III/IV cancer ( $76 \%$ versus $20 \%$, respectively). ORR among patients with serum CEA level higher than $5.0 \mathrm{ng} / \mathrm{ml}$ was significantly higher than that among those with lower serum levels (88\% versus $38 \%$, respectively). ECOG PS, tumor location, histological grade, and serum CEA level at baseline might be useful predictors of cetuximab efficacy in the first-line treatment of mCRC.
\end{abstract}

\section{Keywords}

Cetuximab, Colorectal Cancer, Clinical Predictor 


\section{Introduction}

Improvement of treatment outcomes to colorectal cancer (CRC) is a matter of public health concern in developed countries. In Japan, CRC is the fourth most common cancer in men (115.9 per 10,000 population) and the second most common in women ( 80.5 per 100,000 population), and CRC mortality is the third highest in men (42.9 per 100,000 population) and the highest in women (34.6 per 100,000 population) among the mortality rates for various cancers.

Cetuximab is an agent against epidermal growth factor receptor (EGFR). The expression of EGFR is detected with a high probability in CRC, and associated with poor prognosis and survival [1] [2] [3]. Cetuximab, a chimeric IgG1 monoclonal antibody against EGFR, binds to EGFR with high affinity and blocks ligand-induced activation of EGFR. In Japan, this agent was recently approved as an agent against EGFR-positive metastatic or recurrent CRC [4]. More outcome data of cetuximab for Japanese patients in clinical practice is desired.

Some EGFR downstream signal pathways have been revealed to be biomarkers of cetuximab efficacy. KRAS exon 2 mutations are the most common biomarker for predicting the efficacy of anti-EGFR antibodies in advanced CRC [5]. KRAS (exon 3,4), NRAS (exon 2, 3, 4) and BRAF mutations are also predictive biomarkers [6] [7]. Also, recently, amphiregulin and epiregulin, which belong to the epidermal growth factor (EGF) family, were reported as predictive biomarkers of cetuximab [8] [9]. However, it is difficult to utilize these factors as biomarkers of efficacy in clinical use. The primary tumor site (left- or right-sided) has been demonstrated as a useful biomarker for predicting efficacy of cetuximab treatment in several studies [10] [11]. This is a very clinically useful predictor, and the National Comprehensive Cancer Network (NCCN) Guidelines for Colon Cancer V. 1. 2017 state that panitumumab and cetuximab combination therapy is only recommended for left-sided tumors. However, other convenient clinical predictors have not been sufficiently revealed.

In the present study, we assessed clinical efficacy and adverse effects of cetuximab-based regimen for advanced mCRC. In addition, we explored possible new clinically convenient predictors of this regimen.

\section{Patients and Methods}

\subsection{Patients and Treatments}

All 30 patients with KRAS exon 2 wild-type unresectable metastatic CRC (mCRC) who had been treated with cetuximab-based regimen as first-line therapy at Okayama Rosai Hospital between August 2011 and December 2015 were retrospectively analyzed. Patients were treated with cetuximab and either FOLFOX (oxaliplatin, folinic acid, and 5-FU), FOLFIRI (5-FU, folinic acid, and irinotecan), or SOX (S-1 and oxaliplatin). Cetuximab was given at an initial dose of $400 \mathrm{mg}$ per square meter of body-surface area, followed by a weekly maintenance infusion of $250 \mathrm{mg}$ per square meter. All patients had measurable lesions according to Response Evaluation Criteria in Solid Tumors (RECIST; ver- 
sion 1.1) [12]. This study was approved by the institutional review board of Okayama Rosai Hospital. Written informed consent was obtained from all patients.

\subsection{KRAS Mutation Analysis}

Formalin-fixed, paraffin-embedded (FFPE) samples of tumor tissue from archival specimens were collected at the time of diagnosis. DNA samples were obtained from the FFPE samples, and genomic DNA was extracted. Mutations in KRAS were detected using the multiplex PCR-Luminex method-based MEBGEN Mutation Kit (Medical \& Biological Laboratories, Nagoya, Japan).

\subsection{Assessment}

Eastern Cooperative Oncology Group Performance Status (ECOG PS) was used to evaluate each patient's performance status at baseline [13]. The histological grade of CRC was assessed based on the percentage of glandular differentiation in the tumor according to the World Health Organization (WHO) criteria [14]. Radiologic assessments of tumors were performed by investigators every about 8 weeks, and Response Evaluation Criteria in Solid Tumors (RECIST) version 1.1 was used to assess tumor responses. Various toxicities (rash, anorexia, malaise, fatigue, nervous system disorders, nausea and vomiting, stomatitis, constipation, diarrhea, and alopecia) were evaluated each time the patients visited the hospital, and graded according to the Common Terminology Criteria for Adverse Events (CTCAE), version 4.0.

\subsection{Statistical Analyses}

Differences in objective response rate (ORR) between groups were examined using the Fisher's exact test for categorical variables. Progression-free survival (PFS) and overall survival (OS) curves were generated using the Kaplan-Meier method. To uncover clinical predictive factors, the log-rank test was used. Values of $P<0.05$ were considered to be significant. All statistical analyses were performed with EZR (Saitama Medical Centre, Jichi Medical University), which is a graphical user interface for $\mathrm{R}$ (The R Foundation for Statistical Computing, version 3.2.2) [15].

\section{Results}

\subsection{Patient Characteristics}

A total of 30 patients with KRAS exon 2 wild-type unresectable mCRC who were treated with cetuximab-based regimen as first-line therapy were included in the study. The sample population comprised 22 males and 8 females, with median age 67 years (range, 32 - 85 years). Among the 30 patients, 23 had left-, and 7 had right-sided CRC; 26 had ECOG PS of 0 to 1 , and 4 had PS of 2 to 3; 23 had all-RAS wild-type; and 5 had low (III/IV) histological grade cancer. Carcinoembryonic antigen (CEA) levels at baseline of 17 patients were more than 5.0 
ng/ml. Patients received cetuximab-based regimens including FOLFOX (20 patients), SOX (4 patients), and FOLFIRI (6 patients); 7 patients had experienced oxaliplatin-based adjuvant chemotherapy. The patient background characteristics are listed in Table 1.

\subsection{Treatment Outcomes}

Clinical outcomes are shown in Table 2. For all patients, the ORR was 67\%, and the disease control rate (DCR) was $83 \%$. The median OS was 32.7 months (95\% CI, 23.2 - 44.8 months; Figure 1(a)) and the median PFS was 8.1 months (95\% CI, 7.0 - 14.0 months; Figure 1(b)). Only 1 patient, who underwent treatment with mFOLFOX6 plus cetuximab regimen, had complete response. At the time of analysis, 27 patients (90\%) had already finished treatment, and the median treatment period was 7.3 months (range, 1 - 18 months).

Table 1. Patient characteristics.

\begin{tabular}{|c|c|c|}
\hline Parameter & & \\
\hline \multirow[t]{2}{*}{ Gender, n (\%) } & Male & $22(73)$ \\
\hline & Female & $8(27)$ \\
\hline Age (years) & Median (range) & $67(32-85)$ \\
\hline \multirow[t]{2}{*}{ Primary tumor site, $\mathrm{n}(\%)$} & Right-sided & $7(23)$ \\
\hline & Left-sided & $23(77)$ \\
\hline \multirow[t]{2}{*}{ KRAS wild type, n (\%) } & Yes & $30(100)$ \\
\hline & No & $0(0)$ \\
\hline \multirow[t]{2}{*}{ Other RAS genotype, n (\%) } & Wild-type & $23(77)$ \\
\hline & Mutant-type & $7(23)$ \\
\hline \multirow[t]{2}{*}{ ECOG PS at baseline, $\mathrm{n}(\%)$} & $0-1$ & $26(87)$ \\
\hline & $2-3$ & $4(13)$ \\
\hline \multirow[t]{2}{*}{ Organs with metastases, n (\%) } & $0-2$ & $25(83)$ \\
\hline & 3 & $5(17)$ \\
\hline \multirow[t]{2}{*}{ Lymph node metastasis at baseline, n (\%) } & Positive & $15(50)$ \\
\hline & Negative & $15(50)$ \\
\hline \multirow[t]{2}{*}{ Peritoneal metastasis at baseline, $\mathrm{n}(\%)$} & Positive & $6(20)$ \\
\hline & Negative & $24(80)$ \\
\hline \multirow[t]{2}{*}{ Histological grade, $\mathrm{n}(\%)$} & $1-2$ & $25(83)$ \\
\hline & $3-4$ & $5(17)$ \\
\hline \multirow[t]{2}{*}{ CEA at baseline, $\mathrm{n}(\%)$} & $<5.0 \mathrm{ng} / \mathrm{ml}$ & $13(43)$ \\
\hline & $\geq 5.0 \mathrm{ng} / \mathrm{ml}$ & $17(57)$ \\
\hline \multirow[t]{3}{*}{ Treatment regimen, $\mathrm{n}(\%)$} & FOLFOX & $20(67)$ \\
\hline & SOX & $4(13)$ \\
\hline & FOLFILI & $6(20)$ \\
\hline \multirow[t]{2}{*}{ Oxaliplatin-based adjuvant chemotherapy, n (\%) } & Yes & $7(23)$ \\
\hline & No & $23(77)$ \\
\hline
\end{tabular}




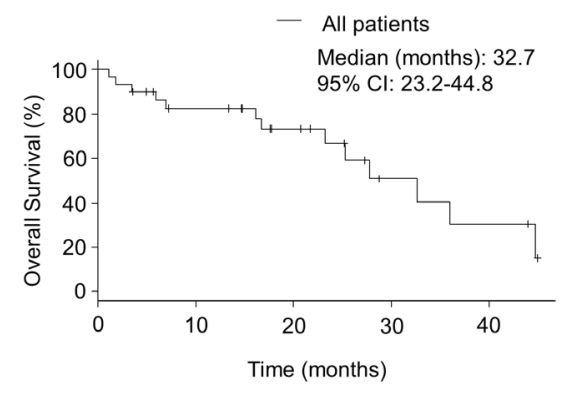

(a)

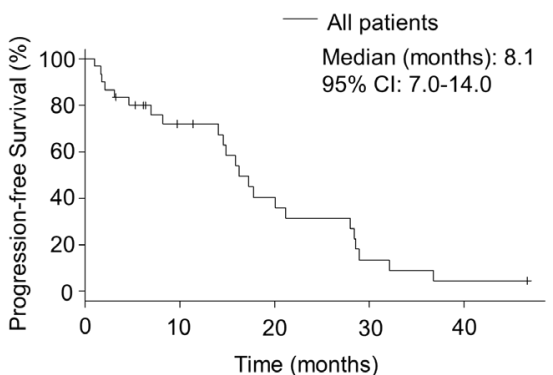

(b)

Figure 1. Overall survival and progression-free survival. Kaplan-Meier curves for (a) overall survival among all 30 patients, (b) progression-free survival among all 30 patients.

Table 2. Treatment characteristics.

\begin{tabular}{ccc}
\hline Parameter & & \\
\hline Treatment response, $\mathrm{n}(\%)$ & Complete response & $1(3)$ \\
& Partial response & $19(63)$ \\
& Stable disease & $5(17)$ \\
Progression-free survival (months) & Progression disease & $5(17)$ \\
& Median & 8.1 \\
Overall survival (months) & $95 \%$ CI & $7.0-14.0$ \\
& Median & 32.7 \\
& $95 \%$ CI & $23.2-44.8$ \\
\hline
\end{tabular}

\subsection{Clinical Predictors of Cetuximab-Based Regimen}

ORR, PFS, and OS were compared respectively with various factors (Table 3). Factors with a differential outcome of ORR or PFS may reflect predictive markers for cetuximab efficacy.

When factors were analyzed for ORR, high histological grade and serum CEA level showed significant interaction with good clinical effect. Patients with histological grade I/II cancer experienced better ORR than those with histological grade III/IV cancer ( $76 \%$ versus $20 \%$, respectively; $P=0.031$ ). ORR among patients with serum CEA level higher than $5.0 \mathrm{ng} / \mathrm{ml}$ was significantly higher than that among those with lower than $5.0 \mathrm{ng} / \mathrm{ml}$ (88\% versus $38 \%$, respectively; $P=$ 0.0069).

In analysis of PFS, left-sided tumor and good PS had significant relevance to good results. Median PFS in left-sided CRC patients was 10.6 months, significantly longer than that in right-sided CRC patients (3.5 months; log-rank test, $P$ $=0.00031$ ). Patients with a PS of $0-1$ experienced significantly longer PFS than those with a PS of $2-3$ (median, 8.6 months versus 1.3 months, respectively; log-rank test, $P=0.0030$ ).

\subsection{Adverse Effects}

Adverse events were evaluable in 28 of 30 patients, and are detailed in Table 4. No adverse events of grade 4 were observed. 
Table 3. Association between clinical factors and treatment outcome.

\begin{tabular}{|c|c|c|c|c|c|c|c|}
\hline \multirow[b]{2}{*}{ Parameter } & \multirow[b]{2}{*}{$\mathrm{n}$} & \multicolumn{2}{|c|}{$\begin{array}{l}\text { Treatment } \\
\text { response }\end{array}$} & \multicolumn{2}{|c|}{$\begin{array}{l}\text { Progression-free } \\
\quad \text { survival }\end{array}$} & \multicolumn{2}{|c|}{$\begin{array}{l}\text { Overall } \\
\text { survival }\end{array}$} \\
\hline & & $\begin{array}{c}\text { ORR } \\
(\%)\end{array}$ & $\begin{array}{c}P \text { value } \\
\text { (Fisher test) }\end{array}$ & $\begin{array}{l}\text { Median } \\
\text { (months) }\end{array}$ & $\begin{array}{c}P \text { value } \\
\text { (log-rank } \\
\text { test) }\end{array}$ & $\begin{array}{l}\text { Median } \\
\text { (months) }\end{array}$ & $\begin{array}{c}P \text { value } \\
\text { (log-rank } \\
\text { test) }\end{array}$ \\
\hline \multicolumn{8}{|l|}{ Gender } \\
\hline Male & 22 & 73 & 0.38 & 8.6 & 0.26 & 36.0 & 0.33 \\
\hline Female & 8 & 50 & & 7.0 & & 25.3 & \\
\hline \multicolumn{8}{|l|}{ Age (years) } \\
\hline$<75$ & 23 & 74 & 0.18 & 8.6 & 0.85 & 27.8 & 0.47 \\
\hline$\geq 75$ & 7 & 43 & & 7.3 & & 32.7 & \\
\hline \multicolumn{8}{|c|}{ Primary tumor site } \\
\hline Right-sided & 7 & 43 & 0.18 & 3.5 & 0.00031 & 16.7 & 0.025 \\
\hline Left-sided & 23 & 74 & & 10.6 & & 36.0 & \\
\hline \multicolumn{8}{|c|}{ Other RAS genotype } \\
\hline Wild-type & 23 & 70 & 0.66 & 10.0 & 0.089 & 36.0 & 0.26 \\
\hline Mutant-type & 7 & 57 & & 7.9 & & 23.2 & \\
\hline \multicolumn{8}{|c|}{ ECOG PS at baseline } \\
\hline $0-1$ & 26 & 73 & 0.095 & 8.6 & 0.0030 & 32.7 & 0.000013 \\
\hline $2-3$ & 4 & 25 & & 1.3 & & 4.4 & \\
\hline \multicolumn{8}{|c|}{$\begin{array}{l}\text { Lymph node metastasis } \\
\text { at baseline }\end{array}$} \\
\hline Positive & 15 & 73 & 0.70 & 8.1 & 0.40 & 32.7 & 0.70 \\
\hline Negative & 15 & 60 & & 8.9 & & 25.3 & \\
\hline \multicolumn{8}{|c|}{$\begin{array}{l}\text { Peritoneal metastasis } \\
\text { at baseline }\end{array}$} \\
\hline Positive & 6 & 67 & 1 & 8.6 & 1.0 & 27.8 & 0.21 \\
\hline Negative & 24 & 67 & & 8.1 & & 32.7 & \\
\hline \multicolumn{8}{|c|}{$\begin{array}{l}\text { Histological grade } \\
\text { at baseline }\end{array}$} \\
\hline $1-2$ & 25 & 76 & 0.031 & 8.6 & 0.13 & 36.0 & 0.022 \\
\hline $3-4$ & 5 & 20 & & 1.5 & & 23.2 & \\
\hline \multicolumn{8}{|l|}{ CEA at baseline } \\
\hline$<5.0 \mathrm{ng} / \mathrm{ml}$ & 13 & 38 & 0.0069 & 4.1 & 0.40 & 23.2 & 0.0043 \\
\hline$\geq 5.0 \mathrm{ng} / \mathrm{ml}$ & 17 & 88 & & 10.0 & & 44.8 & \\
\hline \multicolumn{8}{|c|}{$\begin{array}{l}\text { Oxaliplatin-including } \\
\text { treatment regimen }\end{array}$} \\
\hline Yes & 24 & 71 & 0.37 & 8.1 & 0.74 & 36.0 & 0.069 \\
\hline No & 6 & 50 & & 8.9 & & 23.2 & \\
\hline \multicolumn{8}{|c|}{$\begin{array}{l}\text { Oxaliplatin-based } \\
\text { adjuvant chemotherapy }\end{array}$} \\
\hline Yes & 7 & 57 & 0.66 & 8.1 & 0.44 & 32.7 & 0.79 \\
\hline No & 23 & 70 & & 8.9 & & 27.8 & \\
\hline
\end{tabular}


Table 4. Adverse events.

\begin{tabular}{|c|c|c|}
\hline \multirow{2}{*}{ Adverse Events } & Any Grades & $>$ Grade 3 \\
\hline & \multicolumn{2}{|c|}{ No. of patients (\%) } \\
\hline Rash & $26(93)$ & $3(11)$ \\
\hline Anorexia & $25(89)$ & $0(0)$ \\
\hline Malaise & $25(89)$ & $0(0)$ \\
\hline Fatigue & $23(82)$ & $0(0)$ \\
\hline Nervous system disorders & $23(82)$ & $0(0)$ \\
\hline Nausea and vomiting & $22(79)$ & $0(0)$ \\
\hline Stomatitis & $19(68)$ & $0(0)$ \\
\hline Constipation & $17(61)$ & $0(0)$ \\
\hline Diarrhea & $12(43)$ & $2(7)$ \\
\hline Alopecia & $12(43)$ & $0(0)$ \\
\hline
\end{tabular}

All patients had experienced an adverse event. The most frequent adverse event was rash, observed among 26 of 28 patients. Grade 3 adverse events observed in the present study were rash ( 3 patients) and diarrhea ( 2 patients).

\section{Discussion}

Personalized treatment of patients with $\mathrm{mCRC}$ is becoming routine in clinical practice. Cetuximab-based therapy is among the mCRC treatments, and has been performed in selected patients. Formerly, cetuximab was used for unselected patients with EGFR-positive mCRC based on trial NCIC CTG CO.17 and BOND trial results [4] [16]. Subsequently, significant interactions between KRAS status and cetuximab treatment effect were noted in the CRYSTAL trial, and similar results were obtained from past trials [5] [6]. Further subgroup analysis in CRYSTAL validated all-RAS mutations as negative predictors for cetuximab therapy [7]. Also, recent studies have found that location of CRC (right-sided versus left-sided) is a useful predictor of cetuximab treatment outcome. In trial CALGB/SWOG80405, impact of primary tumor site on OS and PFS in patients with KRAS wild-type mCRC was analyzed [17]. PFS of patients with left-sided primary tumor was significantly longer than those with right-sided primary tumor (12.0 months versus 7.7 months, respectively). Several other studies had reported similar outcomes, and the National Comprehensive Cancer Network (NCCN) Guidelines for Colon Cancer V. 1. 2017 state that panitumumab and cetuximab combination therapies are only recommended for left-sided tumors.

In the present study, we explored predictors using ORR and PFS as indicators of efficacy. In total, 30 patients with KRAS exon 2 wild-type unresectable mCRC received cetuximab-based regimen as first-line therapy. As a result, left-sided CRC, good PS, well/moderately differentiated type, and high serum level of CEA showed relations to good clinical response. Patients with left-sided CRC had sig- 
nificantly better PFS than those with right-sided CRC (10.6 months versus 3.5 months, respectively; $P=0.00031)$. These results are similar to those of studies so far reported. Also, patients with a PS of 0 - 1 showed significantly longer PFS than those with a PS of 2-3. Jonker, D. J., et al. reported that relative benefits of cetuximab in terms of PFS were seen in subgroups defined on the basis of ECOG PS at baseline in trial NCIC CTG CO.17 [16]. Our study indicated that good PS was related to better clinical outcome as well. Our results showed that patients with histological grade I/II cancer experienced better ORR than those with histological grade III/IV cancer. When patients were limited to all RAS wild-type, ORR among 19 patients with histological grade I/II cancer was higher than in the other 4 patients $(79.0 \%$ versus $25.0 \%$, respectively). In CRC, some studies showed an association between EGFR expression and tumor differentiation grade [18] [19] [20]. It is suggested that moderately/well differentiated CRC cells express EGFR activity to a greater extent than poorly differentiated cells. This supports our result, that patients with moderately/well differentiated cancer showed better treatment response than those with poorly differentiated cancer on treatment with cetuximab-based regimen. Poor histological grade is considered among the adverse histopathological factors associated with unfavorable clinical course of CRC. In cetuximab treatment, poor histological grade may be not only an unfavorable prognostic factor, but also an adverse clinical predictor. It was also observed that serum CEA level influenced efficacy of cetuximab-based regimen in this study. ORR among patients with serum CEA level higher than $5.0 \mathrm{ng} / \mathrm{ml}$ was significantly better than that among those with lower serum levels. When patients were limited to all RAS wild-type, ORR among 13 patients with serum CEA level higher than $5.0 \mathrm{ng} / \mathrm{ml}$ was significantly higher than that among 10 patients with lower serum levels (92.3\% versus $40.0 \%$, respectively; Fisher test, $P=0.019$ ). Patients with high serum levels of CEA had better clinical outcome than the other patients, even when limited to all RAS wild-type patients. CEA is a member of the immunoglobulin gene superfamily, and is overexpressed in about $90 \%$ of CRCs [21]. Serum CEA is used as a tumor marker for management of CRC [22]. On the other hand, Bhatnagar et al. noticed that in well differentiated CRC there is more production of CEA/gram of total protein than in the poorly differentiated tumors [23]. In our study, the proportion of patients with serum CEA level higher than $5.0 \mathrm{ng} / \mathrm{ml}$ among histological grade I/II tumor patients was significantly higher than those among histological grade III/IV tumor patients $(68.0 \%$ versus $0 \%$, respectively; Fisher test, $P=0.0090$ ). The present study showed histological tumor grade of patients with high CEA level tended to be moderately/well differentiated, and these patients could experience good treatment response. However, further studies are needed, since this study was retrospective and limited by small sample size.

In Japan, the number of elderly people who need colorectal cancer chemotherapy has increased, as well as in the USA and Europe. Bevacizumab, a monoclonal antibody against vascular endothelial growth factor-A, was reported to be clinically useful for aged mCRC patients in the AVEX trial [24]. In contrast, the 
cetuximab treatment for aged patients with mCRC is still considered to be debatable. The efficacy and adverse effects of the cetuximab-based medication for aged patients have not been thoroughly assessed. Our study included aged patients (over the age of 75), and compared them statistically against non-aged patients (under the age of 75). Among the aged patients, ORR was $43 \%$, and DCR was $100 \%$ (data not shown). Median PFS and median OS were 7.3 months and 32.7 months, respectively. There were no significant differences at all in clinical outcomes between aged patients and non-aged patients. Incidence of adverse effects was also the same (data not shown). Cetuximab treatments for aged patients were not less efficacious compared with non-aged patients in some sub-analysis of other past studies. Our results in clinical practice also showed that cetuximab-based regimen was effective and tolerable for aged patients.

\section{Conclusion}

Good PS, left-sided CRC, high serum level of CEA, and well/moderately differentiated type showed associations with good clinical efficacy. ECOG PS, tumor location, histological grade, and serum CEA level at baseline might be useful predictors of cetuximab efficacy in the first-line treatment of mCRC.

\section{Acknowledgements}

We sincerely thank the participating patients and their families. We also thank Ms. Hamada and the entire medical staff who contributed to patient care.

\section{Conflict of Interest}

The authors declare that they have no conflict of interest.

\section{References}

[1] Goldstein, N.S. and Armin, M. (2001) Epidermal Growth Factor Receptor Immunohistochemical Reactivity in Patients with American Joint Committee on Cancer Stage Iv Colon Adenocarcinoma: Implications for a Standardized Scoring System. Cancer, 92, 1331-1346. https://doi.org/10.1002/1097-0142(20010901)92:5<1331::AID-CNCR1455>3.0.CO;2 $\underline{-\mathrm{M}}$

[2] Mayer, A., Takimoto, M., Fritz, E., Schellander, G., Kofler, K. and Ludwig, H. (1993) The Prognostic Significance of Proliferating Cell Nuclear Antigen, Epidermal Growth Factor Receptor, and Mdr Gene Expression in Colorectal Cancer. Cancer, 71, 2454-2460.

https://doi.org/10.1002/1097-0142(19930415)71:8<2454::AID-CNCR2820710805>3. $\underline{0 . \mathrm{CO} ; 2-2}$

[3] Porebska, I., Harlozinska, A. and Bojarowski, T. (2000) Expression of the Tyrosine Kinase Activity Growth Factor Receptors (Egfr, Erb B2, Erb B3) in Colorectal Adenocarcinomas and Adenomas. Tumour Biology: The Journal of the International Society for Oncodevelopmental Biology and Medicine, 21, 105-115. https://doi.org/10.1159/000030116

[4] Cunningham, D., Humblet, Y., Siena, S., Khayat, D., Bleiberg, H., Santoro, A., Bets, 
D., Mueser, M., Harstrick, A., Verslype, C., Chau, I. and Van Cutsem, E. (2004) Cetuximab Monotherapy and Cetuximab Plus Irinotecan in Irinotecan-Refractory Metastatic Colorectal Cancer. New England Journal of Medicine, 351, 337-345. https://doi.org/10.1056/NEJMoa033025

[5] Karapetis, C.S., Khambata-Ford, S., Jonker, D.J., O’Callaghan, C.J., Tu, D., Tebbutt, N.C., Simes, R.J., Chalchal, H., Shapiro, J.D., Robitaille, S., Price, T.J., Shepherd, L., $\mathrm{Au}$, H.J., Langer, C., Moore, M.J. and Zalcberg, J.R. (2008) K-Ras Mutations and Benefit from Cetuximab in Advanced Colorectal Cancer. The New England Journal of Medicine, 359, 1757-1765. https://doi.org/10.1056/NEJMoa0804385

[6] Van Cutsem, E., Kohne, C.H., Lang, I., Folprecht, G., Nowacki, M.P., Cascinu, S., Shchepotin, I., Maurel, J., Cunningham, D., Tejpar, S., Schlichting, M., Zubel, A., Celik, I., Rougier, P. and Ciardiello, F. (2011) Cetuximab Plus Irinotecan, Fluorouracil, and Leucovorin as First-Line Treatment for Metastatic Colorectal Cancer: Updated Analysis of Overall Survival According to Tumor Kras and Braf Mutation Status. Journal of Clinical Oncology: Official Journal of the American Society of Clinical Oncology, 29, 2011-2019. https://doi.org/10.1200/JCO.2010.33.5091

[7] Van Cutsem, E., Lenz H.J., Kohne, C.H., Heinemann, V., Tejpar, S., Melezinek, I., Beier, F., Stroh, C., Rougier, P., van Krieken, J. H. and Ciardiello, F. (2015) Fluorouracil, Leucovorin, and Irinotecan Plus Cetuximab Treatment and Ras Mutations in Colorectal Cancer. Journal of Clinical Oncology: Official Journal of the American Society of Clinical Oncology, 33, 692-700. https://doi.org/10.1200/JCO.2014.59.4812

[8] Lo Nigro, C., Ricci, V., Vivenza, D., Granetto, C., Fabozzi, T., Miraglio, E. and Merlano, M.C. (2016) Prognostic and Predictive Biomarkers in Metastatic Colorectal Cancer Anti-Egfr Therapy. World journal of gastroenterology, 22, 6944-6954.

https://doi.org/10.3748/wjg.v22.i30.6944

[9] Jonker, D.J., Karapetis, C.S., Harbison, C., O’Callaghan, C.J., Tu, D., Simes, R.J., Malone, D.P., Langer, C., Tebbutt, N., Price, T.J., Shapiro, J., Siu, L.L., Wong, R.P., Bjarnason, G., Moore, M.J., Zalcberg, J.R. and Khambata-Ford, S. (2014) Epiregulin Gene Expression as a Biomarker of Benefit from Cetuximab in the Treatment of Advanced Colorectal Cancer. British Journal of Cancer, 110, 648-655. https://doi.org/10.1038/bjc.2013.753

[10] Brule, S.Y., Jonker, D.J., Karapetis, C.S., O'Callaghan, C.J., Moore, M.J., Wong, R., Tebbutt, N.C., Underhill, C., Yip, D., Zalcberg, J.R., Tu, D. and Goodwin, R.A. (2015) Location of Colon Cancer (Right-Sided Versus Left-Sided) as a Prognostic Factor and a Predictor of Benefit from Cetuximab in Ncic Co.17. European Journal of Cancer (Oxford, England: 1990), 51, 1405-1414.

https://doi.org/10.1016/j.ejca.2015.03.015

[11] Von Einem, J.C., Heinemann, V., von Weikersthal, L.F., Vehling-Kaiser, U., Stauch, M., Hass, H.G., Decker, T., Klein, S., Held, S., Jung, A., Kirchner, T., Haas, M., Holch, J., Michl, M., Aubele, P., Boeck, S., Schulz, C., Giessen, C., Stintzing, S. and Modest, D.P. (2014) Left-Sided Primary Tumors Are Associated with Favorable Prognosis in Patients with Kras Codon 12/13 Wild-Type Metastatic Colorectal Cancer Treated with Cetuximab Plus Chemotherapy: An Analysis of the Aio Krk-0104 Trial. Journal of Cancer Research and Clinical Oncology, 140, 1607-1614. https://doi.org/10.1007/s00432-014-1678-3

[12] Eisenhauer, E.A., Therasse, P., Bogaerts, J., Schwartz, L.H., Sargent, D., Ford, R., Dancey, J., Arbuck, S., Gwyther, S., Mooney, M., Rubinstein, L., Shankar, L., Dodd, L., Kaplan, R., Lacombe, D. and Verweij, J. (2009) New Response Evaluation Criteria in Solid Tumours: Revised Recist Guideline (Version 1.1). European Journal of Cancer (Oxford, England: 1990), 45, 228-247. 
[13] Oken, M.M., Creech, R.H., Tormey, D.C., Horton, J., Davis, T.E., McFadden, E.T. and Carbone, P.P. (1982) Toxicity and Response Criteria of the Eastern Cooperative Oncology Group. American Journal of Clinical Oncology, 5, 649-655. https://doi.org/10.1097/00000421-198212000-00014

[14] Barresi, V., Reggiani Bonetti, L., Ieni, A., Caruso, R.A. and Tuccari, G. (2015) Histological Grading in Colorectal Cancer: New Insights and Perspectives. Histology and Histopathology, 30, 1059-1067.

[15] Kanda, Y. (2013) Investigation of the Freely Available Easy-to-Use Software "Ezr" for Medical Statistics. Bone Marrow Transplantation, 48, 452-458. https://doi.org/10.1038/bmt.2012.244

[16] Jonker, D.J., O’Callaghan, C.J., Karapetis, C.S., Zalcberg, J.R., Tu, D., Au, H.J., Berry, S.R., Krahn, M., Price, T., Simes, R.J., Tebbutt, N.C., van Hazel, G., Wierzbicki, R., Langer, C. and Moore, M.J. (2007) Cetuximab for the Treatment of Colorectal Cancer. The New England Journal of Medicine, 357, 2040-2048. https://doi.org/10.1056/NEJMoa071834

[17] Venook, A.P., Niedzwiecki, D., Innocenti, F, et al. (2016) Impact of Primary (10) Tumor Location on Overall Survival (Os) and Progression-Free Survival (Pfs) in Patients (Pts) with Metastatic Colorectal Cancer (Mcrc): Analysis of Calgb/Swog 80405 (Alliance). Journal of Clinical Oncology, 34, 3504-3504.

[18] McKay, J.A., Murray, L.J., Curran, S., Ross, V.G., Clark, C., Murray, G.I., Cassidy, J. and McLeod, H.L. (2002) Evaluation of the Epidermal Growth Factor Receptor (Egfr) in Colorectal Tumours and Lymph Node Metastases. European Journal of Cancer (Oxford, England: 1990), 38, 2258-2264.

[19] Steele, R.J., Kelly, P., Ellul, B. and Eremin, O. (1990) Immunohistochemical Detection of Epidermal Growth Factor Receptors on Human Colonic Carcinomas. British Journal of Cancer, 61, 325-326. https://doi.org/10.1038/bjc.1990.63

[20] Steele, R.J., Kelly, P., Ellul, B. and Eremin, O. (1990) Epidermal Growth Factor Receptor Expression in Colorectal Cancer. The British Journal of Surgery, 77, 1352-1354. https://doi.org/10.1002/bjs.1800771211

[21] Goldstein, M.J. and Mitchell, E.P. (2005) Carcinoembryonic Antigen in the Staging and Follow-Up of Patients with Colorectal Cancer. Cancer Investigation, 23, 338-351. https://doi.org/10.1081/CNV-58878

[22] Locker, G.Y., Hamilton, S., Harris, J., Jessup, J.M., Kemeny, N., Macdonald, J.S., Somerfield, M.R., Hayes, D.F. and Bast, R.C. (2006) Asco 2006 Update of Recommendations for the Use of Tumor Markers in Gastrointestinal Cancer. Journal of Clinical Oncology: Official Journal of the American Society of Clinical Oncology, 24, 5313-5327. https://doi.org/10.1200/JCO.2006.08.2644

[23] Bhatnagar, J., Tewari, H.B., Bhatnagar, M. and Austin, G.E. (1999) Comparison of Carcinoembryonic Antigen in Tissue and Serum with Grade and Stage of Colon Cancer. Anticancer Research, 19, 2181-2187.

[24] Cunningham, D., Lang, I., Marcuello, E., Lorusso, V., Ocvirk, J., Shin, D.B., Jonker, D., Osborne, S., Andre, N., Waterkamp, D. and Saunders, M.P. (2013) Bevacizumab plus Capecitabine versus Capecitabine Alone in Elderly Patients with Previously Untreated Metastatic Colorectal Cancer (Avex): An Open-Label, Randomised Phase 3 Trial. The Lancet Oncology, 14, 1077-1085. 
Submit or recommend next manuscript to SCIRP and we will provide best service for you:

Accepting pre-submission inquiries through Email, Facebook, LinkedIn, Twitter, etc. A wide selection of journals (inclusive of 9 subjects, more than 200 journals)

Providing 24-hour high-quality service

User-friendly online submission system

Fair and swift peer-review system

Efficient typesetting and proofreading procedure

Display of the result of downloads and visits, as well as the number of cited articles Maximum dissemination of your research work

Submit your manuscript at: http://papersubmission.scirp.org/

Or contact jet@scirp.org 